\title{
Umbilical Cord Constriction: A Case Report
}

\author{
Rajeev Agarwal ${ }^{1}$, Apoorva P Reddy ${ }^{2}$, Ankita Kaushal ${ }^{3}$
}

\begin{abstract}
The reason for sudden antenatal death syndrome (SADS) are not well established. Umbilical cord accidents (UCA) are one of the causes of SADS. In UCA, umbilical venous and/or umbilical arterial flow is compromised and leads to intrapartum death of the foetus. Presenting here is a case report of cord constriction leading to late second trimester intrauterine foetal death.

Keywords: Constriction, Cord anomaly, Cord compression, Intrauterine foetal death, Still birth, Umbilical cord.

Journal of South Asian Federation of Obstetrics and Gynaecology (2019): 10.5005/jp-journals-10006-1727
\end{abstract}

\section{INTRODUCTION}

Sudden antenatal death syndrome (SADS) is not only an emotionally challenging scenario for the mother but also a medically dicey situation for the treating physician. Although most conditions do not have a plausible explanation, umbilical cord accidents (UCAs) are one of the causes of SADS. In UCA, umbilical venous and/or umbilical arterial flow is compromised and leads to intrapartum death of the fetus. Commonly associated causes are cord prolapse, true knot, thrombosis of umbilical vessels, cord entanglement, and sustained cord compression. Rarely, cord constriction is reported as the cause. We presenting here a case report of cord constriction leading to late second trimester intrauterine fetal death.

\section{Case Description}

The patient Mrs Preeti Bansal, 30 years old, G2P2L1, previous lower segment cesarean section (LSCS), registered antenatal care (ANC) case, reported with a USG report suggestive of IUFD at 28 weeks, with no preceding warning signs, complications, or incidents. Her first trimester screening was in the low-risk category. Comprehensive anomaly scan was performed at 18 weeks of gestation and was recorded within normal limits. On a routine scan of 28 weeks by USG [ 27 weeks 5 days by last menstrual period (LMP)], no cardiac activity was reported. The umbilical cord was reported as normal, three-vessel cord.

There was no other identifiable maternal medical disorder. Also, there was no identifiable social or family history.

Hysterotomy was performed, at 28 weeks i/v/o previous LSCS.

Delivered a male baby of $1.1 \mathrm{~kg}$.

On delivery of the fetal placental unit, on further examination, a constriction was noted at the site of fetal insertion of the umbilical cord (Fig. 1). It was sent for histopatholigical examination (HPE). Placental insertion was normal. There were no other gross placental anomaly or fetal anomaly (Fig. 2). There were no signs of placental separation, and the remaining length of the umbilical cord was normal in appearance and length. The postpartum period was uneventful (Fig. 3).

\section{Histopathology Report}

Figure 4.

\section{Discussion}

Constriction of the umbilical cord is characterized by absence of Wharton's jelly (proteoglycan connective tissue in which umbilical
1,3 International Fertility Academy, Kolkata, West Bengal, India

${ }^{2}$ International Fertility Academy, Bengaluru, Karnataka, India

Corresponding Author: Apoorva P Reddy, International Fertility Academy, Bengaluru, Karnataka, India, e-mail: dr.apoorvavijay@gmail. com

How to cite this article: Agarwal R, Reddy AP, Kaushal A. Umbilical Cord Constriction: A Case Report. J South Asian Feder Obst Gynae 2019;11(6):389-391.

Source of support: Nil

Conflict of interest: None

vessels are embedded). It leads to narrowing of the cord, and hence the umbilical vessels are more susceptible to constriction due to mechanical pressure. This may lead to compromised blood supply, fetal anoxia, and eventually intrauterine fetal death.

Very few cases, around 50 is past three centuries, have been reported in the world literature. Exact causes leading to umbilical cord constriction are not known; amniotic band syndrome (1 of $100,000-150,000$ ) is one of the causes. ${ }^{1}$ Few cases have also been reported following amniocentesis. Torsion of the umbilical cord has been first reported as the cause of IUFD (as early as 1691 by Ruysch), rarely associated with constriction. In the literature reviewed by Dohrn (1861), 85 cases of torsion were found. There were few

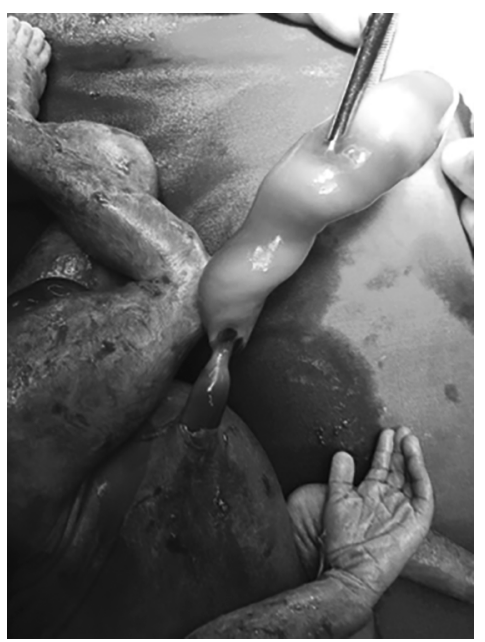

Fig. 1: Attachment of the umbilical cord at the fetal end

(-) The Author(s). 2019 Open Access This article is distributed under the terms of the Creative Commons Attribution 4.0International License (https://creativecommons. org/licenses/by-nc/4.0/), which permits unrestricted use, distribution, and non-commercial reproduction in any medium, provided you give appropriate credit to the original author(s) and the source, provide a link to the Creative Commons license, and indicate if changes were made. The Creative Commons Public Domain Dedication waiver (http://creativecommons.org/publicdomain/zero/1.0/) applies to the data made available in this article, unless otherwise stated. 
mentions of localized constriction of the umbilical cord. It was Burdacsh (1758) who first described the combination of torsion and constriction. Dohrn reported a case of constriction and torsion at the fetal end and expressed his views that torsion was primary to constriction, which led to fetal death. Cavasse (1865) reported a case of constriction only and also mentioned thrombosis of the umbilical vein and complete absence of Wharton's jelly in the

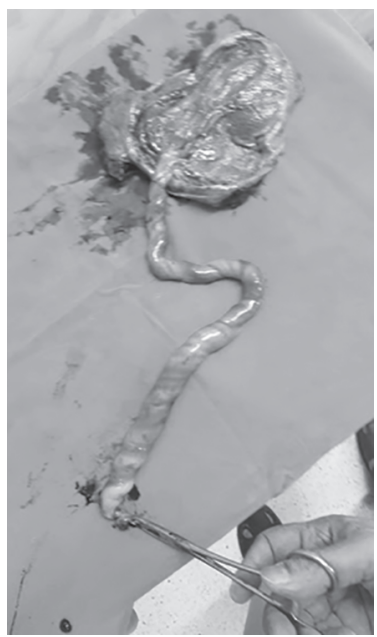

Fig. 2: Placenta and remaining length of the umbilical cord constricted part. Similar etiology was proposed by Browne (1925), reporting thrombosis of both umbilical arteries and the narrow lumen of the vein.

Fewer cases have been reported reading the recurrence of umbilical cord stricture. A case report by French et al. ${ }^{2}$ reported intrauterine fetal demise of three out of four fetuses of a single patient. All three IUFDs were due to cord stricture at fetal insertion, and the fourth surviving baby was an emergency delivery at 25 weeks.

A study conducted by Sun et al. ${ }^{3}$ reviewed 25 cases reported since 1995 and other 8 new cases. They reported that only associated symptom was decreased fetal movements during second or third trimester. Higher incidence is noted in twin gestation. Most of the fetuses are macerated and constriction of the umbilical cord is seen commonly at the fetal end and rarely at the placental end. Major pathological features are loss or absence of Wharton's jelly, stenosis or obliteration of cord vessels, and intravascular thrombosis.

Umbilical cord stricture can also be associated with cord overcoiling as suggested by Peng et al. ${ }^{4}$

No standard modalities are available for prenatal diagnosis of this condition. In a recent study, Tian et al., ${ }^{5}$ suggested that radiodiagnosis evaluation comprising of pitch value of cord coiling and the SD flow velocity ratio of umbilical cord artery in various cord segments may help predict cord torsion. However, they did not specifically recommend the use of this technique during routine fetal US survey examinations.

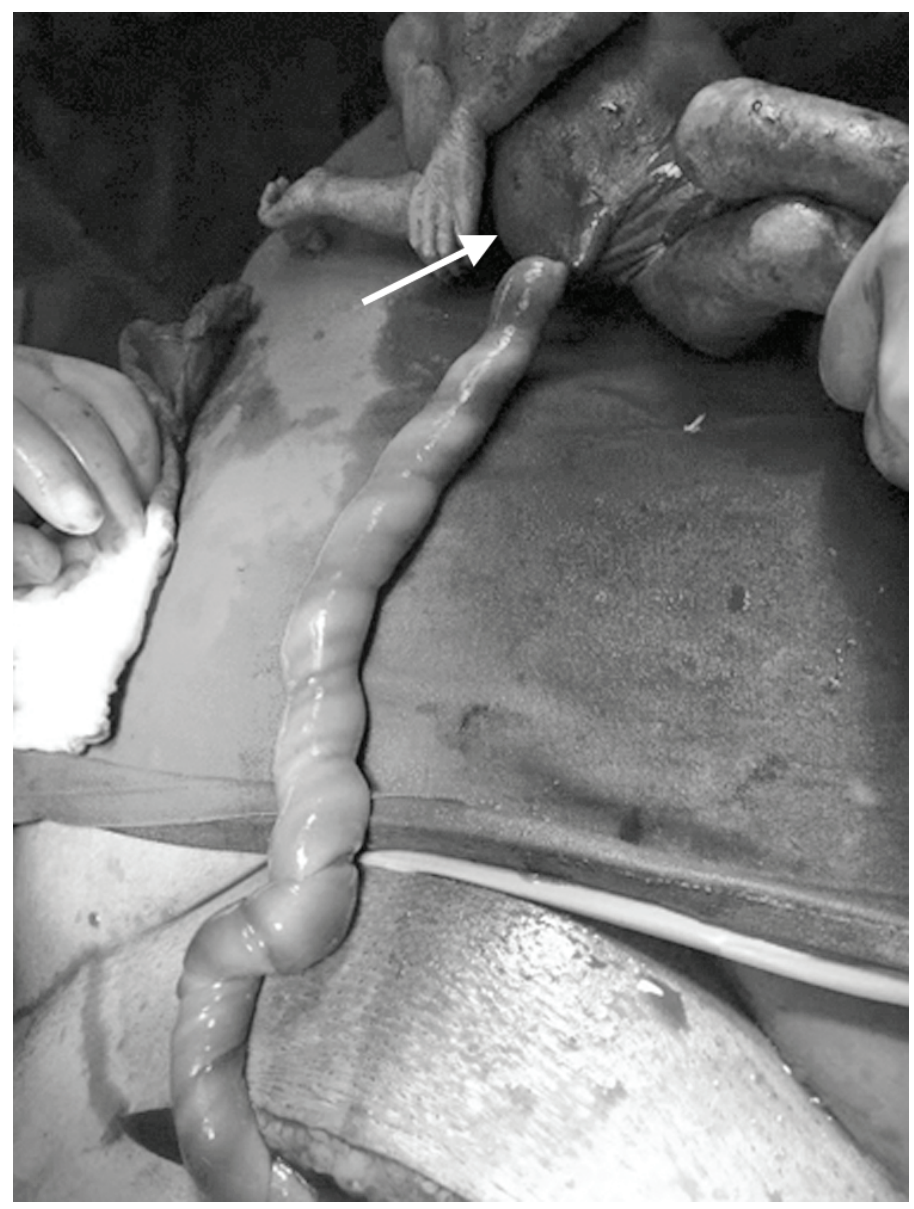

Fig. 3: Cord constriction immediately post delivery of the fetus 


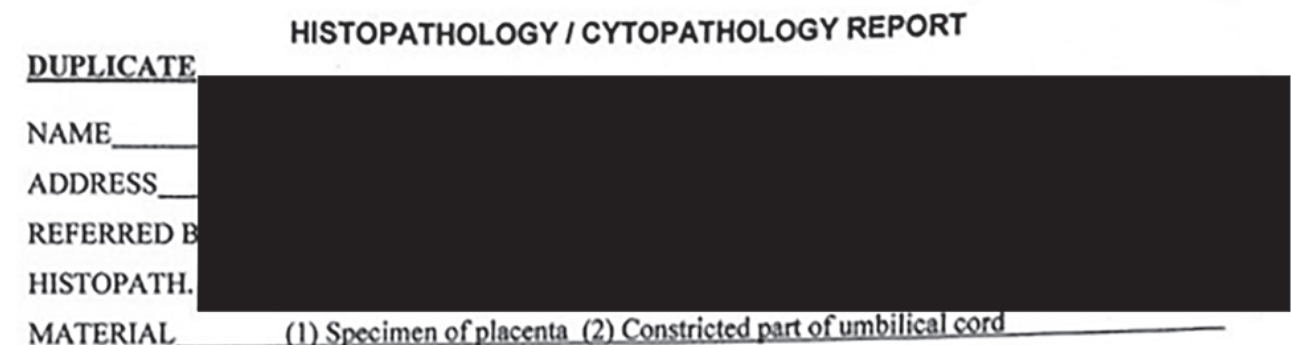

Lab No. E 13791

Clinical information provided -

Case of IUFD at 28 weeks in a case of post caesarian section pregnancy.

Thick umbilical cord with constriction before point of entry at umbilicus.

GROSS :- $\quad$ Two specimens received -

1) Specimen of placenta, measuring $14 \mathrm{~cm} . \times 12 \mathrm{~cm} . \times 4 \mathrm{~cm}$. with an umbilical cord $35 \mathrm{~cm}$. in length; the whole specimen weighs $438.6 \mathrm{gms}$. The umbilical cord is thickened and shows three vessels. The membranes are congested. The cut surface of the placenta is pale.

Block keys :- A-E -different areas of umbilical cord, F-K - different areas of placenta, LM membranes.

2) Constricted part of umbilical cord, measuring $2.5 \mathrm{~cm}$. in length. (NO)

(Grossed by : Dr. A.R)

MICROSCOPICAL EXAMINATION :-

Multiple sections examined from the placenta and umbilical cord. The villi shows increased syncytial knots. There is intervillous fibrin deposition. The villi are congested and show prominent blood vessels. No other specific pathology detected. The membranes are congested. Sheets of decidual cells are present.

The umbilical cord shows three vessels which are congested. The Wharton's jelly of the constricted part of the umbilical cord shows areas of infaretion and karyorrhectic debris.

IMPRESSION :- Placenta is showing ischaemic changes probably as a consequence of umbilical stricture.

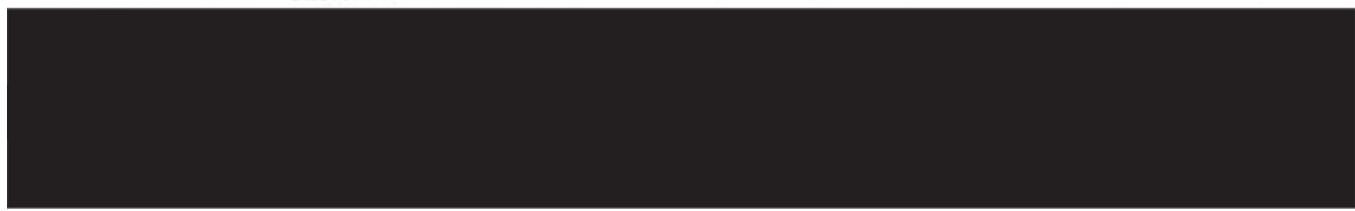

(Pleaso seo ovorieaf)

Fig. 4: Copy of the histopathology report

\section{ConcLusion}

The exact etiology of umbilical cord stricture is still not clear. The recurrence risk is also not known. The couple should be adequately counseled. More cases and data are required to know the causes and mechanism of the absence of Wharton's jelly leading to cord stricture.

\section{References}

1. Heifetz SA. Strangulation of the umbilical cord by amniotic bands: report of 6 cases and literature review. Pediatr Pathol 1984;2(3): 285-304. DOI: 10.3109/15513818409022261.
2. French $A E$, Gregg $\mathrm{VH}$, Newberry $\mathrm{Y}$, et al. Umbilical cord stricture: a cause of recurrent fetal death. Obstet Gynecol 2005;105(5 Pt 2): 1235-1239. DOI: 10.1097/01.AOG.0000159041.55845.f7.

3. Sun $Y$, Arbuckle $S$, Hocking $G$, et al. Umbilical cord stricture and intrauterine fetal death. Pediatr Pathol Lab Med 1995;15(5):723-732. DOI: 10.3109/15513819509027008.

4. Peng HQ, Levitin-Smith M, Rochelson B, et al. Umbilical cord stricture and overcoiling are common causes of fetal demise. Pediatr Dev Pathol 2006;9(1):14-19. DOI: 10.2350/05-05-0051.1.

5. Tian CF, Kang MH, Wu W, et al. Relationship between pitch value or S/D ratio of torsion of cord and fetal outcome. Prenat Diagn 2010;30(5):454-458. DOI: 10.1002/pd.2499. 